\title{
A Swine Model of Horse Serum-Induced Coronary Vasculitis: An Implication for Kawasaki Disease
}

\author{
SAJI PHILIP, WEN-CHUAN LEE, SI-KWANG LIU, MEI-HWAN WU, AND HUNG-CHI LUE \\ Division of Biotechnology [S.P., W.-C.L., S.-K.L.], Cardiovascular Research Center, Animal Technology \\ Institute, Miaoli 350, Taiwan; Division of Pediatric Cardiology [S.P., M.-H.W., H.-C.L.], Department of \\ Pediatrics, National Taiwan University College of Medicine, Taipei 100, Taiwan; Min-Sheng General \\ Hospital [S.P., H.-C.L.], Taoyuan 330, Taiwan; and Animal Medical Center [S.-K.L.], New York, New \\ York 10021-8302, U.S.A.
}

\begin{tabular}{|c|c|}
\hline \multicolumn{2}{|c|}{ ABSTRACT } \\
\hline $\begin{array}{l}\text { An attempt was made to induce immune complex vasculitis } \\
\text { by horse serum (HS) infusions in piglets, hoping to produce } \\
\text { experimental coronary artery lesions that mimic Kawasaki dis- } \\
\text { ease. A total of } 21 \text { purebred male piglets of } 1.5,2.5 \text {, and } 3 \text { mo } \\
\text { were divided into HS ( } n=14 \text { ) and control, normal saline (NS; } \\
n=7 \text { ) groups. In seven piglets, } 5 \mathrm{~mL} / \mathrm{kg} \text { of HS was infused, then } \\
\text { repeated with } 10 \mathrm{~mL} / \mathrm{kg} 10 \mathrm{~d} \text { later. In another seven piglets, } 10 \\
\mathrm{~mL} / \mathrm{kg} \text { of HS was infused three times at } 5 \text {-d intervals. In three } \\
\text { piglets in the control group, } 5 \text { and } 10 \mathrm{~mL} / \mathrm{kg} \text { of NS was infused } \\
\text { at } 10 \text {-d intervals. In another four piglets of the control group, } 10 \\
\mathrm{~mL} / \mathrm{kg} \text { of NS was infused three times at } 5 \text {-d intervals. Two- } \\
\text { dimensional echocardiographic examinations for visualization } \\
\text { and measurement of the coronary arteries were done before and } \\
\text { after infusions at } 4 \text { - to } 5 \text {-d interval. Hematology examination } \\
\text { showed that white blood cells and platelets decreased, then } \\
\text { increased. The animals were killed at } 14-60 \mathrm{~d} \text { after the first } \\
\text { infusion of HS or NS, for histopathologic and immunohisto- } \\
\text { chemical studies. All HS groups developed skin rashes and } \\
\text { echocardiographic evidence of coronary artery dilation and his- }\end{array}$ & $\begin{array}{l}\text { topathologic changes of vasculitis. None in the NS group devel- } \\
\text { oped vasculitis. The main changes of the coronary vasculitis } \\
\text { were intimal proliferation, smooth muscle cell necrosis, and } \\
\text { vacuolization changes. Those that received three HS infusions } \\
\text { developed more skin rashes than those that received two infu- } \\
\text { sions. It is concluded that piglets may serve as an experimental } \\
\text { model for immune complex vasculitis involving the coronary } \\
\text { arteries with skin rashes mimicking Kawasaki disease. (Pediatr } \\
\text { Res 55: 211-219, 2004) } \\
\text { CAL, coronary artery lesion } \\
\text { HS, horse serum } \\
\text { IC, immune complex } \\
\text { KD, Kawasaki disease } \\
\text { LCA, left coronary artery } \\
\text { NS, normal saline } \\
\text { RCA, right coronary artery } \\
\text { VEGF, vascular endothelial growth factor }\end{array}$ \\
\hline
\end{tabular}

Kawasaki disease (KD), an acute self-limiting systemic vasculitis of unknown origin, has become a leading cause of acquired heart disease other than rheumatic heart disease in many developed countries (1-3). Coronary artery lesions (CALs) with aneurysmal dilation, thrombosis, and/or stenosis, leading to myocardial infarction and death, have been recognized as the most severe complication (4, 5). Circulating immune complexes (ICs), triggered by infectious agents, bacteria, or viral or other unknown cause, have been detected in

Received October 25, 2002; accepted September 2, 2003.

Correspondence: Hung-Chi Lue, M.D., Ph.D., Department of Pediatrics, National Taiwan University College of Medicine, and Min-Sheng General Hospital, 168, ChingKuo Rd, Taoyuan 330, Taiwan; e-mail: hclue@e-ms.com.tw

Supported by Animal Technology Institute Taiwan (National Science Council grant no. 89-2313-8-059-036), Cardiac Children's Foundation, and Min-Sheng General Hospital.

DOI: 10.1203/01.PDR.0000104151.26375.E5 the early phase of KD, implicating that immunopathologic mechanisms might be involved in the pathogenesis of vasculitis in $\mathrm{KD}(6-10)$. Attempts to produce coronary vasculitis have been made in mice, weanling rabbits, and guinea pigs by injecting infectious agents, foreign proteins, and Lactobacillus casei cell walls (11-15). Coronary arteritis was induced in weanling rabbits by injecting horse serum (HS) (16). Swine is a unique and promising animal for biomedical research, especially in the field of cardiovascular diseases $(17,18)$. IC coronary vasculitis, however, was never produced in swine. We tried, therefore, to induce coronary vasculitis in piglets, hoping that CAL mimicking KD could be produced. This study was designed to observe the skin and systemic reactions and hematologic changes, measure the coronary artery diameters by echocardiography, and examine the histopathologic and immunochemical changes of the coronary and systemic arteries 
in 14 piglets after HS infusions and in seven control piglets infused with normal saline (NS). The implications to KD are discussed.

\section{METHODS}

Experimental animal. A total of 21 purebred castrated piglets, weighing 9-39 kg, aged 1.5-3 mo, randomly selected from a certified farm of national nuclear herd of the Animal Technology Institute Taiwan were subjected to this study. They were equivalent to human age of 3 mo to $1 \mathrm{y}$ as per the percentage of maturation and metabolic age chart (19). The design of this study was approved by the Institutional Review Board of the Animal Technology Institute Taiwan, and the care and handling of piglets followed the guidelines of the Animal Protection Law, Council of Agriculture (20). The HS group consisted of 14 piglets, aged $1.5 \mathrm{mo}(n=2), 2.5 \mathrm{mo}(n=10)$, and 3 mo $(n=2)$, and the NS group consisted of seven piglets, aged $1.5 \mathrm{mo}(n=1), 2.5 \mathrm{mo}(n=4)$, and $3 \mathrm{mo}(n=2)$.

Procedures. Piglets were anesthetized by ketamine HCL (5-10 $\mathrm{mg} / \mathrm{kg}$ body weight), azaperone (Stresnil; $8-10 \mathrm{mg} / \mathrm{kg}$ i.m.), or thiamylal sodium (Cytosol; $5-8 \mathrm{mg} / \mathrm{kg}$ i.v.), alone or in combination. In each of seven piglets, $5 \mathrm{~mL}(2.6 \mathrm{~g}$ protein) $/ \mathrm{kg}$ of HS (Cat. No. 16270-035, Lot No. 1026238; GIBCO BRL Life Technologies, Gaithersburg, MD, U.S.A.; $<5 \%$ gamma globulin, virus, and mycoplasma negative) was infused slowly, then another $10 \mathrm{~mL}(5.2 \mathrm{~g}$ protein $) / \mathrm{kg}$ of HS was infused $10 \mathrm{~d}$ later in the same way. To another seven piglets, 10 $\mathrm{mL}(5.2 \mathrm{~g}$ protein $) / \mathrm{kg}$ of HS was infused i.v. three times at 5 -d intervals. In three piglets in the control group, $5 \mathrm{~mL} / \mathrm{kg}$ of NS was administered i.v., then the second dose of $10 \mathrm{~mL} / \mathrm{kg}$ of NS was infused $10 \mathrm{~d}$ later. In another four piglets in the control group, $10 \mathrm{~mL} / \mathrm{kg}$ of NS was given three times at 5-d intervals. Before and $60 \mathrm{~min}$ after the HS or NS infusions, whole blood was sampled from either the jugular or the femoral vein for the measurement of leukocyte, red blood cell, and platelet counts and $\mathrm{Hb}$, cholesterol, alanine aminotransferase, and aspartate aminotransferase levels.

Echocardiography. Two-dimensional (2-D) echocardiographic examinations were performed using Hewlett Packard
Sonos 100 . The diameters of the left coronary artery (LCA) and right coronary artery (RCA) were checked and measured at 4- to 5-d intervals before and after the HS or NS infusion. For the comparison study of their diameter changes, measurements of the diameter were taken $5 \mathrm{~mm}$ from the orifice of RCA and LCA. All measurements were taken on the modified parasternal long axis and short axis and modified apical four-chamber views in both right and left lateral positions. All piglets were carefully observed before and after infusions until the day of autopsy. Intraobserver and interobserver measurements were tested.

Tissue collection and histochemistry. Autopsy was performed at 14, 24, 34, 41, or $60 \mathrm{~d}$ after the first dose of HS or NS infusion. Gross appearance and histopathology of the LCA, $\mathrm{RCA}$, and left anterior descending and left circumflex coronary arteries and of the myocardium and systemic arteries such as aorta, and subclavian, iliac, and femoral arteries were checked and studied. The liver, kidney, spleen, ear, and skin were also studied. All tissue specimens were perfused and put in $10 \%$ phosphate-buffered formaldehyde. All materials were serially sectioned into segments of 2- to 3-mm thickness, and slides were prepared in hematoxylin and eosin stain. Other special stains, such as Masson's trichrome and van Gieson stains for collagen and ground substances and Ver Hoefe stain for internal elastic membrane, were also obtained.

Immunohistochemistry. After deparaffinization, tissue sections were treated with $0.05 \%$ trypsin for $30 \mathrm{~min}$ at $37^{\circ} \mathrm{C}$. After washing three times in PBS, the sections again were treated with $3 \%$ hydrogen peroxide for $10 \mathrm{~min}$ at $37^{\circ} \mathrm{C}$, and then washed three times in PBS. Nonspecific antibody binding was blocked by incubation with 5\% normal goat serum for $20 \mathrm{~min}$ at room temperature. The sections were then incubated at $37^{\circ} \mathrm{C}$ with rabbit anti-human vascular endothelial growth factor (VEGF; diluted 1:100) polyclonal antibody for $1 \mathrm{~h}$ (Cat No. 500-P10, Lot No. 099CY10; Petro Tech EC Ltd, Cambridgeshire, UK). The sections were washed three times in PBS and incubated with biotinylated secondary antibody (Vector Laboratories, Burlingame, CA, U.S.A.) for $30 \mathrm{~min}$ at $37^{\circ} \mathrm{C}$. The sections were then treated with peroxidase conjugated with

Table 1. Skin rashes and systemic reactions after HS infusions

\begin{tabular}{|c|c|c|c|c|c|c|c|c|c|c|}
\hline \multirow{2}{*}{$\begin{array}{c}\text { Case } \\
\text { no. }\end{array}$} & \multirow{2}{*}{$\begin{array}{l}\text { No. of HS } \\
\text { infusions }\end{array}$} & \multicolumn{7}{|c|}{ Rashes } & \multirow[b]{2}{*}{ Cyanosis } & \multirow{2}{*}{$\begin{array}{c}\text { Respiratory } \\
\text { distress }\end{array}$} \\
\hline & & Ear & Mouth & Perineal & Abdomen & Thorax & Back & Legs & & \\
\hline 01 & 2 & - & + & + & + & + & + & + & + & - \\
\hline 03 & 2 & - & - & - & + & - & - & - & - & - \\
\hline 04 & 2 & + & + & + & + & + & + & + & + & + \\
\hline 05 & 2 & + & + & + & + & - & - & + & + & - \\
\hline 06 & 2 & + & - & + & - & - & - & + & - & - \\
\hline 08 & 3 & ++ & - & ++ & - & - & - & - & - & - \\
\hline 09 & 3 & + & - & ++ & ++ & + & + & + & - & + \\
\hline 10 & 3 & ++ & - & ++ & - & ++ & - & ++ & - & - \\
\hline 11 & 3 & - & - & - & - & ++ & - & - & - & - \\
\hline 12 & 3 & + & + & ++ & + & ++ & + & + & + & - \\
\hline 13 & 3 & - & - & + & ++ & + & + & - & - & - \\
\hline 14 & 3 & - & - & + & + & ++ & ++ & - & - & - \\
\hline
\end{tabular}

+ , present; -, absent. 
avidin-biotin complex for $30 \mathrm{~min}$ at $37^{\circ} \mathrm{C}$. After the last wash in PBS, slides were developed by incubation with diaminobenzidine until color development was seen. The slides were then counterstained with Mayer's hematoxylin and mounted for light microscopy.

Statistical analysis. Analysis was carried out using the computer statistical package SPSS (version 7.5) for Windows mean values compared test. Results are expressed as mean \pm SD. Comparison between HS and NS groups was performed by using paired and two-sample $t$ tests. Significance was assigned at $p<0.05$.

\section{RESULTS}

Within 30 min after the first, second, and/or third HS infusion, all piglets showed systemic reactions, such as flushing, tachycardia, and chills. In two piglets, respiratory distress developed, and in four piglets, cyanosis was noted. Erythematous rashes appeared during or immediately after the HS infusion, on the legs in nine (64\%) of 14 piglets, on the chest in eight $(57 \%)$ of 14 , on the ears in eight $(57 \%)$ of 14 , on the mouth lips and perioral areas in five (35\%) of 14 , and at the perineal and perianal regions in $12(86 \%)$ of 14 , as seen in Table 1 and Figure 1. Piglets aged $\geq 2.5$ mo developed more skin rashes than those that were younger. The rashes faded and disappeared in $6-8 \mathrm{~h}$ in the seven piglets that received two infusions and persisted longer, even for $4-5 \mathrm{~d}$, in the seven piglets that received three infusions. None of the NS group showed the skin rashes or systemic reactions.

In the NS group, 2-D echocardiography demonstrated a $12-53 \%$ increase of the diameter of coronary arteries (Table 2 , Fig. 2). The HS group showed a more significant dilation of the LCA and RCA (Table 2, Fig. 3). The coronary artery dilation was more significant in the group that received three infusions than in the group that received two infusions. Of the 14 piglets in the HS group, eight (57\%) showed severe dilation, $100-$ $150 \%$; three $(21 \%)$ showed moderate dilation, $75-99 \%$; and three (21\%) showed mild dilation, $54-74 \%$ (Table 3 ). The coronary artery diameter changes of the NS and HS groups were highly significant $(p<0.001$; Table 4$)$. The mean $\pm 1 \mathrm{SD}$ of intraobserver measurements of the coronary artery diameters was $0.5 \pm 0.05 \mathrm{~mm}$ and that of interobserver measurements was $0.6 \pm 0.08 \mathrm{~mm}$, indicating that the measurements were reproducible.

Hematology pictures showed an abrupt decrease in the white blood cell counts, from an average of $21 \pm 8.7 \times 10^{3}$ to 13.3 $\pm 8.3 \times 10^{3} / \mathrm{mL}$, then followed by an increase up to $26.3 \pm 9.7$ $\times 10^{3} / \mathrm{mL} 7-10 \mathrm{~d}$ after infusion. The average platelet count decreased from $373.3 \pm 123.8 \times 10^{3}$ to $237.1 \pm 114.6 \times$ $10^{3} / \mathrm{mL}$ and then increased up to $552.1 \pm 227.4 \times 10^{3}$. A mild decrease of $\mathrm{Hb}$ levels from $9.8 \pm 1.6$ to $8 \pm 0.5 \mathrm{~g}$ was also observed. No significant changes were noted in the levels of cholesterol, serum alanine aminotransferase, and aspartate aminotransferase $(p \geq 0.05)$.

Histopathologic examinations of coronary and systemic arteries of the NS group showed no significant changes (Fig. 4A). In the HS group, there were many changes of varying intensities, such as internal elastic membrane disruption, mild to
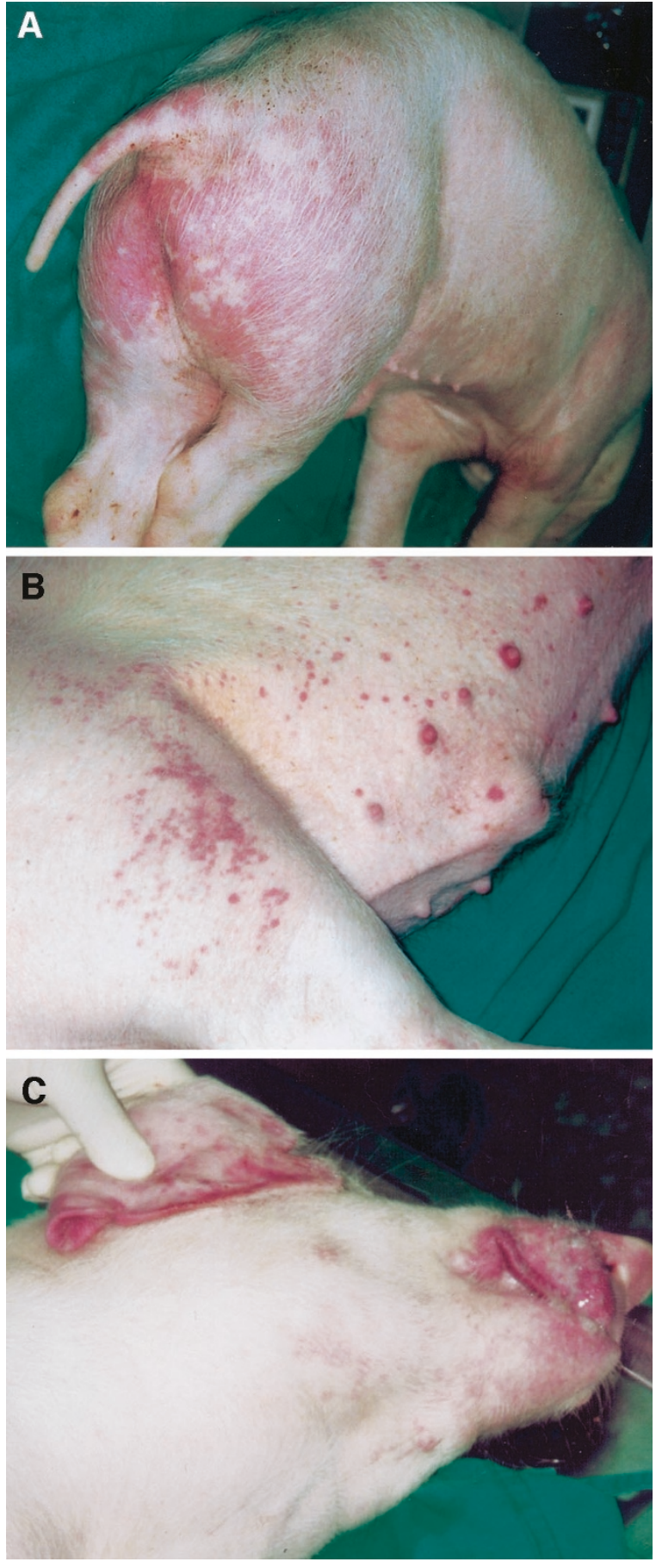

Figure 1. Erythematous rashes $1 \mathrm{~h}$ after an HS infusion in piglet 9. $(A)$ Rashes at the thigh, buttocks, and perianal areas. $(B)$ Rashes at legs, abdomen, and periurethral areas. (C) Rashes at the ear and mouth.

severe intimal proliferative changes, and subintimal changes, such as coagulation of the cytoplasm, and disorientation, separation, cytolysis, vacuolization, degranulation, collagen deposition, total dissociation, and fibrosis of the smooth muscle cells (Fig. 4B-F, Table 5). Histopathology of the skin biopsy taken from the site of rashes showed perivascular infiltrations (Fig. $4 G$ ). Arteritis changes of varying degrees were noted in $100 \%$ of left main coronary (LMC) and left anterior descending (LAD) and in $86 \%$ of RCA. Arteritis changes of mild degrees, such as disruption of internal elastic membrane, or 
Table 2. Data summary of coronary artery enlargement in HS and control saline groups

\begin{tabular}{|c|c|c|c|c|c|c|c|c|c|c|}
\hline \multirow[b]{2}{*}{ Case no. } & \multirow[b]{2}{*}{$\begin{array}{l}\text { Age } \\
\text { (mo) }\end{array}$} & \multirow[b]{2}{*}{$\begin{array}{l}\text { No. of } \\
\text { infusions }\end{array}$} & \multirow{2}{*}{$\begin{array}{c}\text { Wt }(\mathrm{kg}) \\
\text { before and } \\
\text { at autopsy }\end{array}$} & \multicolumn{3}{|c|}{ LCA } & \multicolumn{3}{|c|}{$\mathrm{RCA}$} & \multirow[b]{2}{*}{$\begin{array}{l}\text { Day at } \\
\text { autopsy }\end{array}$} \\
\hline & & & & $\begin{array}{c}\text { Before } \\
(\mathrm{mm})\end{array}$ & $\begin{array}{l}\text { Max } \\
(\mathrm{mm})\end{array}$ & $\begin{array}{c}\text { Enlarged } \\
(\%)\end{array}$ & $\begin{array}{c}\text { Before } \\
(\mathrm{mm})\end{array}$ & $\begin{array}{l}\text { Max } \\
(\mathrm{mm})\end{array}$ & $\begin{array}{c}\text { Enlarged } \\
(\%)\end{array}$ & \\
\hline \multicolumn{11}{|l|}{ HS group } \\
\hline 01. & 1.5 & 2 & $10-12$ & 1.6 & 2.4 & 50 & 2.0 & 3.3 & 65 & D24 \\
\hline 02. & 2.5 & 2 & $20-24$ & 2.0 & 3.0 & 50 & 1.5 & 2.7 & 80 & D14 \\
\hline 03. & 2.5 & 2 & $26-28$ & 2.2 & 4.0 & 90 & 1.4 & 2.3 & 64 & D14 \\
\hline 04. & 2.5 & 2 & $15-24$ & 1.7 & 3.4 & 100 & 2.0 & 3.6 & 80 & D41 \\
\hline 05. & 2.5 & 2 & $25-30$ & 2.2 & 3.7 & 68 & 2.3 & 3.0 & 30 & D34 \\
\hline 06. & 2.5 & 2 & $13-24$ & 2.0 & 2.8 & 40 & 2.1 & 3.2 & 52 & D34 \\
\hline 07. & 1.5 & 2 & $14-35$ & 2.3 & 4.2 & 82 & 1.7 & 3.0 & 76 & D60 \\
\hline 08. & 3.0 & 3 & $26-34$ & 2.0 & 4.5 & 125 & 1.6 & 3.5 & 115 & D24 \\
\hline 09. & 2.5 & 3 & $25-32$ & 1.6 & 4.6 & 187 & 2.0 & 3.8 & 90 & D24 \\
\hline 10. & 2.5 & 3 & $23-26$ & 2.5 & 5.0 & 100 & 2.3 & 3.4 & 47 & D34 \\
\hline 11. & 3.0 & 3 & $32-39$ & 2.7 & 5.4 & 100 & 2.2 & 3.2 & 50 & D34 \\
\hline 12. & 2.5 & 3 & $27-36$ & 2.2 & 4.4 & 100 & 2.0 & 3.1 & 52 & D24 \\
\hline 13. & 2.5 & 3 & $24-34$ & 2.8 & 6.2 & 121 & 2.0 & 2.6 & 18 & D24 \\
\hline 14. & 2.5 & 3 & $24-35$ & 2.6 & 7.6 & 192 & 2.0 & 3.3 & 65 & D24 \\
\hline \multicolumn{11}{|l|}{ NS group } \\
\hline 01. & 3.0 & 2 & $27-37$ & 3.0 & 3.6 & 20 & 2.4 & 3.3 & 37 & D24 \\
\hline 02. & 1.5 & 2 & $9.0-10$ & 1.3 & 2.0 & 53 & 1.6 & 1.8 & 12 & D41 \\
\hline 03. & 2.5 & 2 & $20-31$ & 2.8 & 3.4 & 21 & 2.0 & 2.6 & 30 & D34 \\
\hline 04. & 2.5 & 3 & $16-22$ & 1.8 & 2.4 & 33 & 1.9 & 2.7 & 42 & D14 \\
\hline 05. & 2.5 & 3 & $22-27$ & 2.8 & 2.9 & 35 & 2.2 & 2.6 & 18 & D60 \\
\hline 06. & 3.0 & 3 & $24-28$ & 2.8 & 3.4 & 33 & 2.0 & 2.9 & 40 & D34 \\
\hline 07. & 2.5 & 3 & $26-32$ & 2.4 & 2.8 & 20 & 1.8 & 2.2 & 22 & D24 \\
\hline
\end{tabular}

patchy edematous areas and/or smooth muscle cell proliferation were also noted in systemic arteries with varying percentages: femoral artery, $21 \%$; ascending aorta, $21 \%$; renal, $14 \%$; iliac artery, 14\%; subclavian artery, $14 \%$. No significant changes were observed in the carotid and abdominal aorta. Histopathology of other organs showed no significant changes. Immunohistochemical studies by avidin biotin peroxidase staining showed VEGF antigens in the tunica media and intimal regions in four of 10 piglets in which VEGF staining was done (Fig. 5).

\section{DISCUSSION}

The pathology of KD has been well studied. The pathogenesis of the lesions, however, remains not well understood. Immunopathologic mechanisms may play an important role in the genesis of vasculitis in KD $(6-10)$. Circulating ICs in patients with early-phase KD have been detected $(8,9)$. Onouchi et al. (16) reported that HS-induced IC vasculitis in rabbits was very similar to the pathophysiology of CAL in KD. Swine have been used for the study of cardiovascular diseases $(17,18)$. They are large, omnivorous, and convenient for therapeutic trials $(21,22)$. Heart and vessels are easier to examine with 2-D echocardiography. The coronary artery system is similar to that of humans and is applicable for interventional cardiology, cardiac xenotransplantation, and even heartlung transplantation $(23,24)$. We used the weanling pigs for the experimental animal because of $>80 \%$ of the patients with $\mathrm{KD}$ were infants and children under younger than $5 \mathrm{y}$. To avoid any infection-related vasculitis, we selected GIBCO BRL Life Technologies horse sera, with documented quality control, electrophoretic profile, stability testing, and microbiologic screening especially for Reo virus (25).
IC coronary vasculitis with or without aneurysm has been elicited by various agents in mice, guinea pigs, and weanling rabbits (11-16). The pathogenesis of vasculitis postulated includes the fixation of compliments by ICs, activation of compliment cascade, and the release of biologically active fragments, notably the anaphylatoxins ( $\mathrm{C} 3 \mathrm{a}$ and $\mathrm{C} 5 \mathrm{a}$ ), which increase vascular permeability and yield chemotactic factors for polymorphonuclear leukocytes (26-29). Tissue damage may also be mediated by free radicals produced by activated neutrophils.

After HS infusion, immediate leukopenia followed by leukocytosis we noted in the present study was similar to that reported by Onouchi et al. $(16,30)$. Immediately after the HS infusion, platelets were also significantly decreased and then increased, likewise in $\mathrm{KD}$, as noted by Levin et al. (31). They found that peak platelet count was significantly correlated with the subsequent development of coronary artery aneurysms. ICs, detected by precipitation with polyethylene glycol, also appeared in the circulation as the platelet count increased. Platelets can be activated by many different stimuli, including contact with subendothelial tissues, ICs that bind to Fc receptors on the platelet, platelet-activating factors released from leukocytes, and several toxins or enzymes released by bacteria and viruses $(31,32)$. Cochrane et al. (33) studied the role of platelets in a rabbit model of serum sickness vasculitis, which was similar to the vasculitis of KD where coronary arteries were affected. The platelet IC interaction in pathogenesis of KD was also studied $(31,32)$. Thrombocytosis occurred with a peak usually in the third to fourth week after the onset of KD (34). In our studies, thrombocytosis was the highest 5-7 d after the HS infusion, likewise that found in rabbits by Onouchi et al. (16). Thus, platelets may become hyperaggregable in both 

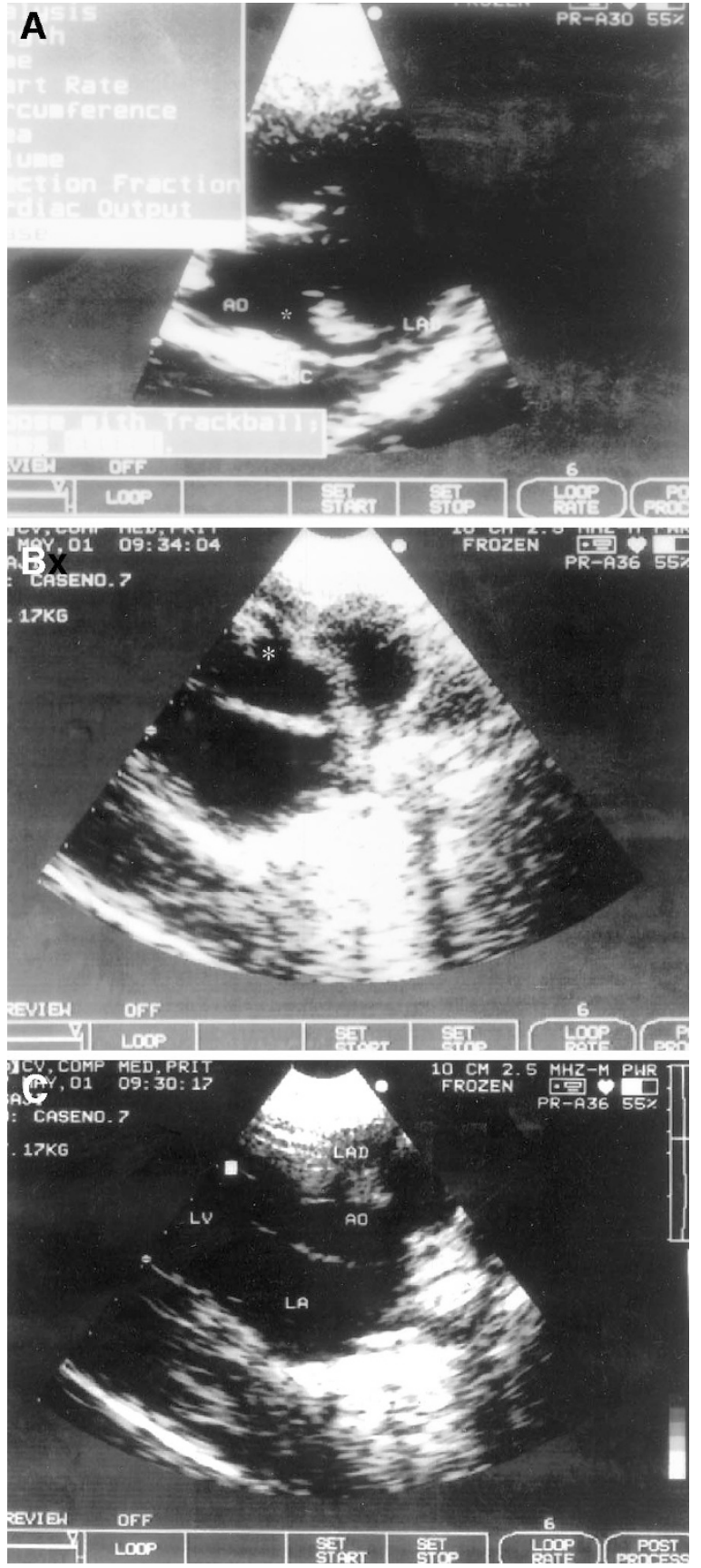

Figure 2. 2-D echocardiographic appearance of coronary arteries in piglet 5 of the NS group. $(A)$ Modified short axis view showing the baseline echocardiogram of LMC orifice (*), LMC, and LAD. (B) Modified parasternal long axis view showing the baseline echocardiogram of LMC and its orifice $(*) .(C)$ Parasternal long axis view showing the baseline echocardiogram of LAD.

acute and convalescent phases of the illness, playing a role, in part, in the pathogenesis of vasculitis in KD (34).

All piglets that received HS infusion in our study developed varying degrees of exanthemas, starting mostly from the perineal regions, then spreading to the trunk, legs, ear, and mouth. The appearance and spreading of the rashes that we observed were somewhat similar to those of KD described by Fritter et al. (35). Indurative edema and peeling of the skin were not observed in our study. Those that received three infusions of HS developed more exanthemas than those that received two
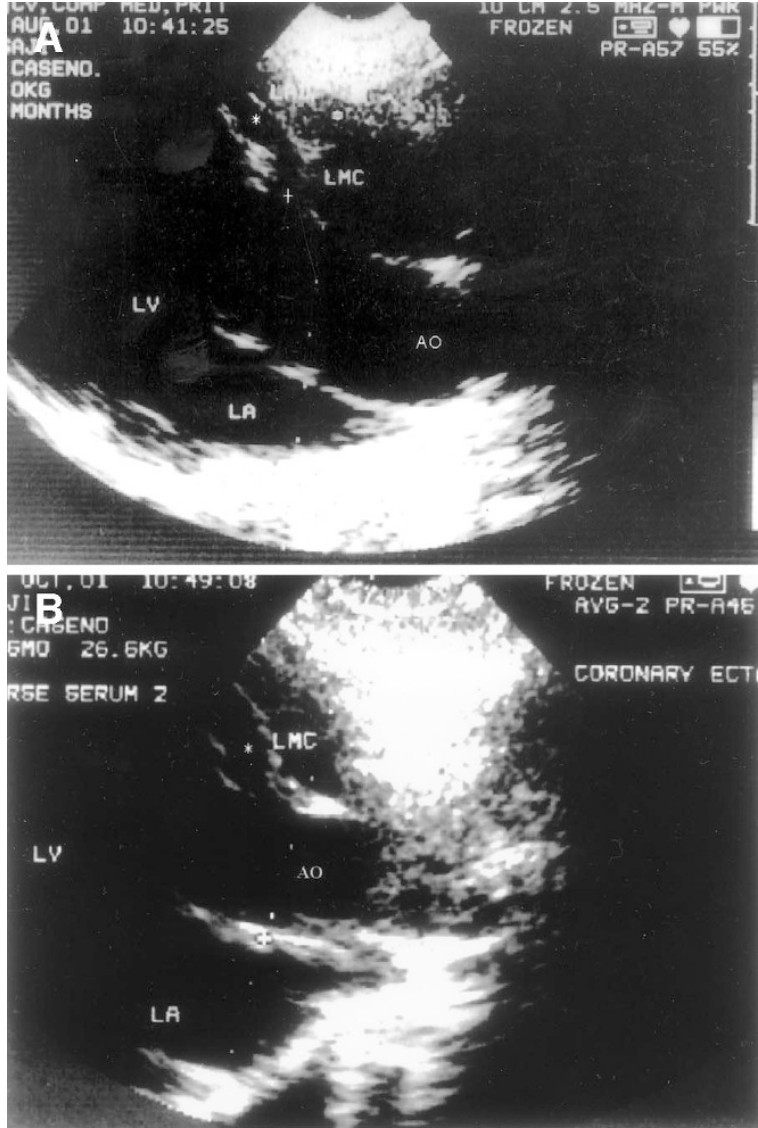

Figure 3. 2-D echocardiogram of enlarged coronary arteries. (A) Modified parasternal long axis view showing dilation of LMC $(+)$ and LAD aneurysm $(*)$ after the first dose of HS infusions in piglet 12 of the HS group. (B) Dilation of LMC (*) measuring $6.2 \mathrm{~mm}$ at day 14 after the first dose of HS infusion in piglet 14 .

Table 3. Coronary artery diameter changes measured by 2-D echocardiography

\begin{tabular}{ccc}
\hline $\begin{array}{c}\text { Diameter \% changes } \\
\text { infusion groups }\end{array}$ & $\begin{array}{c}\text { No. of } \\
\text { piglets }\end{array}$ & $\%$ \\
\hline HS group & 14 & 100.0 \\
$54-74 \%$ & 3 & 21.4 \\
$75-99 \%$ & 3 & 21.4 \\
$100-150 \%$ & 8 & 57.2 \\
NS group & 07 & 100.0 \\
$12-53 \%$ & 7 & 100.0 \\
\hline
\end{tabular}

infusions, suggesting that prolonged and continuous exposure to the sensitizing agent may lead to excess antigen, the formation of small to intermediate IC aggregates, not easily phagocytosed by the macrophages, circulating widely, tending to deposit in the blood vessel walls. Whereas exposure to the sensitizing antigen is low, larger IC aggregates are formed, easily phagocytosed by the macrophages (26-29).

To the best of our knowledge, 2-D echocardiographic studies on the normal coronary artery diameter and its changes in weanling piglets have never been reported. We interpreted the coronary artery dimension as abnormal when the increase was $>12-53 \%$ of the baseline diameter that we observed in the control group (Table 3). Our study showed that coronary artery dilations started to occur 5-10 d after the first infusion of HS. 
Table 4. 2-D echocardiographic studies of coronary artery diameter changes in HS and NS groups

\begin{tabular}{|c|c|c|c|c|c|c|}
\hline & \multicolumn{3}{|c|}{ LCA diameter } & \multicolumn{3}{|c|}{ RCA diameter } \\
\hline $\begin{array}{l}\text { Mean } \\
\text { (SD) }\end{array}$ & $\begin{array}{c}2.24 \\
(0.3)\end{array}$ & $\begin{array}{r}4.45 \\
(1.2)\end{array}$ & $\begin{array}{r}2.21 \\
(1.0)\end{array}$ & $\begin{array}{l}1.86 \\
(0.4)\end{array}$ & $\begin{array}{c}3.14 \\
(0.5)\end{array}$ & $\begin{array}{l}1.28 \\
(0.6)\end{array}$ \\
\hline $\begin{array}{l}p \text { values by } \\
\text { paired } t \text { test }\end{array}$ & \multicolumn{2}{|c|}{$<0.001$} & & \multicolumn{2}{|c|}{$<0.001$} & \\
\hline $\begin{array}{l}\text { Mean } \\
\text { (SD) }\end{array}$ & $\begin{array}{c}2.39 \\
(0.6)\end{array}$ & $\begin{array}{c}3.00 \\
(0.6)\end{array}$ & $\begin{array}{r}0.61 \\
(0.1)\end{array}$ & $\begin{array}{r}2.00 \\
(0.3)\end{array}$ & $\begin{array}{c}2.59 \\
(0.4)\end{array}$ & $\begin{array}{r}0.59 \\
(0.2)\end{array}$ \\
\hline $\begin{array}{l}p \text { values by } \\
\text { paired } t \text { test }\end{array}$ & \multicolumn{3}{|c|}{$<0.001$} & \multicolumn{2}{|c|}{$<0.001$} & \\
\hline $\begin{array}{l}\text { HS vs NS } \\
p \text { values by two } \\
\text { sample } t \text { test }\end{array}$ & 0.474 & 0.007 & $<0.001$ & 0.384 & 0.016 & 0.011 \\
\hline
\end{tabular}

Table 5. Histopathologic changes of coronary arteries and their severity

\begin{tabular}{|c|c|c|c|c|c|c|c|c|c|c|c|c|c|c|}
\hline & \multicolumn{14}{|c|}{ HS group $(n=14)$} \\
\hline No. of infusions & 02 & 02 & 02 & 02 & 02 & 02 & 02 & 03 & 03 & 03 & 03 & 03 & 03 & 03 \\
\hline \multicolumn{15}{|l|}{ LMC } \\
\hline IEM & + & + & + & + & + & + & + & + & + & + & + & + & 0 & 0 \\
\hline Intimal & ++ & 0 & 0 & ++ & ++ & ++ & + & +++ & ++ & ++ & + & +++ & ++ & ++ \\
\hline IEM & + & + & + & 0 & + & + & + & + & + & + & + & + & + & + \\
\hline Intimal & + & + & + & 0 & 0 & + & 0 & ++ & 0 & 0 & + & + & ++ & + \\
\hline SMC & 0 & 0 & +++ & 0 & 0 & 0 & + & 0 & +++ & +++ & 0 & +++ & + & + \\
\hline \multicolumn{15}{|l|}{ LCX } \\
\hline IEM & 0 & 0 & 0 & 0 & + & 0 & 0 & + & 0 & + & + & 0 & 0 & 0 \\
\hline Intimal & 0 & 0 & 0 & 0 & 0 & 0 & 0 & + & 0 & 0 & + & 0 & 0 & 0 \\
\hline SMC & + & 0 & + & ++ & + & ++ & 0 & ++ & 0 & 0 & + & ++ & 0 & + \\
\hline
\end{tabular}

IEM, internal elastic membrane disruption; Intimal, intimal proliferation; SMC, smooth muscle cell changes such as, cell separation, cytolysis, degranulation, and/or total dissociation of smooth muscle cells; LCX, left circumflex.

The echocardiographic findings of CALs observed in the piglets of our present study were similar to those observed in our clinical KD patients (36). An altered lipid profile was found in KD by Newberger et al. (37) but was not found in the piglets that we studied. Long-term follow-up studies might be needed to observe the lipid profile abnormalities in piglets.

The histopathologic changes of coronary arteries that we produced in piglets by HS infusions mimic the subacute to chronic phase changes of coronary vasculitis observed in $\mathrm{KD}$ patients $(38,39)$. In all piglets, the changes were most significant in the tunica media, likewise the initial changes of coronary arteries in $\mathrm{KD}$ occurring in the tunica media at approximately 7-9 $\mathrm{d}$ after the onset of the disease, as reported by Naoe (40). VEGF is one of the most important growth and survival factors for endothelium. It induces angiogenesis and endothelial cell proliferation and plays an important role in regulating vasculogenesis by increasing vascular permeability and vasodilation, partly through stimulation of nitric oxide synthase in endothelial cells $(41,42)$. VEGF can also stimulate cell migration and inhibit apoptosis. In humans, VEGF was significantly elevated during the acute phase of KD (41). The presence of VEGF antigen that we observed in the tunica media and intimal regions of the piglets' coronary arteries is an indirect evidence of vasculitis produced by HS infusion (42).

Our study revealed that induction of IC coronary arteritis was possible in piglets of 9-39 kg, equivalent to infants aged 3-12 mo. Type III hypersensitivity reaction, induced by antigen-antibody complexes, produced tissue damages as a result of their capacity in activating a variety of serum mediators, principally the compliment system. Both ICs and platelets may have some roles in the pathogenesis of vasculitis. Different measuring methods yield varying ICs of different sizes and compositions at different times in the course of a given disease (43). ICs were also identified in the autopsy specimens of KD, suggesting that ICs might have played a role in producing the coronary artery changes in KD patients (43). ICs were also 

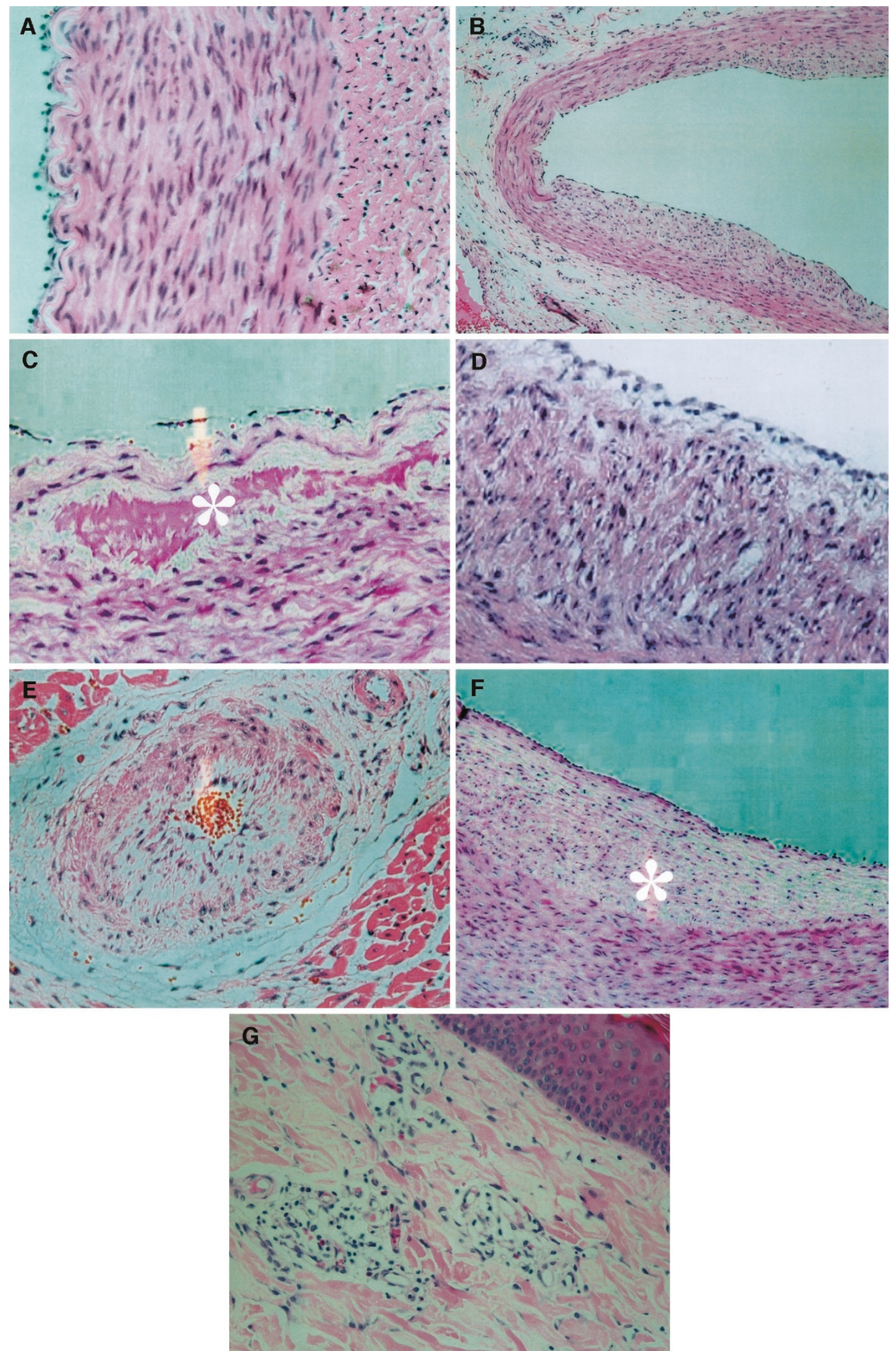

Figure 4. Hematoxylin and eosin staining of arterial walls of piglets. (A) Left anterior descending artery in piglet 9 at day 14 after three NS infusions showing normal-looking intima, internal elastic membrane, tunica media, and adventitia. (B) LAD at day 14 after two HS infusions in piglet 3 showing intimal and subintimal thickening. (C) RCA at day 24 after three HS infusions in piglet 6 showing collagen deposition (light yellow arrow and *) at the subintimal area. $(D$ ) Middle RCA at day 24 after three HS infusions in piglet 1 showing total dissociation of smooth muscle cells of the tunica media, oriented vertically toward the intima. (E) Intramural artery of the left ventricle day 24 after three HS infusions in piglet 8 showing intimal thickening and partial obliteration of the lumen. $(F)$ Iliac artery at day 14 after two HS infusions in piglet 8 showing intimal thickening $(*)$. $(G)$ Skin biopsy from the site of rash at day 5 during the HS infusion in piglet 10 showing perivascular infiltrations. Magnifications: $\times 100$ in $A, F$, and $G ; \times 40$ in $B ; \times 200$ in $C-E$. 


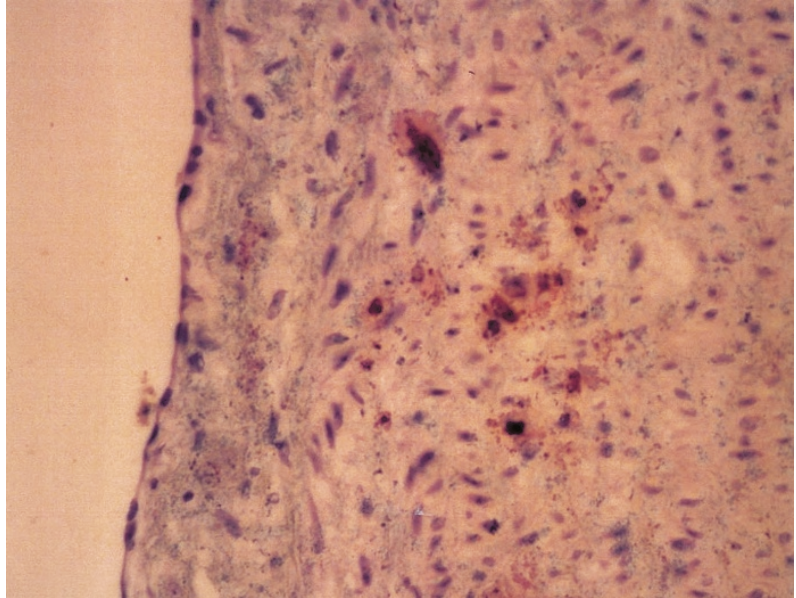

Figure 5. Avidin-biotin peroxidase staining for VEGF. Left main coronary artery at day 24 after three HS infusions in piglet 12 showing positive immunoreactivity for VEGF (brownish aggregates and spots) diffusely in intimal regions and tunica media. Magnification: $\times 200$.

identified in the circulation of the experimental rabbit models with serum sickness (29). The present study documented that systemic type III hypersensitivity reactions to HS infusions in piglets produced vasculitis mimicking KD. We suggest, therefore, that such a similar mechanism may be involved in the pathogenesis of coronary arteritis in $\mathrm{KD}$.

Until now different kinds of protein, such as HS, infectious agents, and bacterial walls, have been used to produce the experimental coronary arteritis (11-16). Of those models, the present animal model is the first experimental model that comes close, mimicking most the clinical pictures of $\mathrm{KD}$, but cannot be called a complete model. It is hoped that a complete $\mathrm{KD}$ experimental model will be developed in the future.

\section{CONCLUSION}

In conclusion, using the HS as the triggering agent, we succeeded in producing coronary artery vasculitis in 14 piglets. CALs were detected by 2-D echocardiography and were proved by histopathology. The rashes, hematoserologic changes, and CALs were similar to KD. We postulate that IC-mediated mechanisms may play a role in the pathogenesis of CALs in KD. A swine model of HS-induced coronary arteritis may serve as an experimental model of KD and may also serve as a model for therapeutic trials and prevention of coronary artery disease in $\mathrm{KD}$.

Acknowledgments. We thank Dr. J.H. Lin, Dr. S.W. How, and Dr. C.H. Hsiao for pathology discussions; Dr. B.S. Tzang, P.H. Lin, and L. Ho for expert technical assistance and autopsy; Dr. M.T. Chiou for immunohistochemical studies; Dr. W.Y. Shau (statistical advice); and Dr. J.K. Wang, Dr. T.J. Lehman, Dr. Z. Onouchi, and Dr. T.S. Yang (inspiration, critical suggestions, controversial thoughts, and advice).

\section{REFERENCES}

1. Kawasaki T 1967 Acute febrile mucocutaneous syndrome with lymphoid involvement with specific desquamation of the fingers and toes in children: clinical observations of 50 cases. Arerugi (Jpn J Allergol) 16:178-222
2. Kawasaki T, Kosaki F, Okawa S, Shigematsu I, Yanagwa H 1974 A new infantile acute febrile mucocutaneous lymph node syndrome (MLNS) prevailing in Japan. Pediatrics 54:271-276

3. Shulman ST, Delnocencio J, Hirsch R 1995 Kawasaki disease. Pediatr Clin North Am 42:1205-1222

4. Fujiwara T, Fujiwara H, Ueda T, Nishioka K, Hamashima Y 1986 Comparison of macroscopic, postmortem, angiographic findings of coronary aneurysms in children with Kawasaki disease. Am J Cardiol 57:761-764

5. Naoe S, Shibuya K, Takahashi K, Wakayama M, Masuda H, Tanaka M 1991 Pathological observations concerning the cardiovascular lesions in Kawasaki disease. Cardiol Young 1:212-220

6. Fossard C, Thompson RA 1977 Mucocutaneous lymph-node syndrome (Kawasaki disease): probable soluble complex disorder. BMJ 1:883-884

7. Weindling AM, Levinsky RJ, Marshall WC, Hood J 1979 Circulating immune complexes in mucocutaneous lymph-node syndrome (Kawasaki disease). Arch Dis Child 54:241-242

8. Furuse A, Matsuda I 1983 Circulating immune complex in the mucocutaneous lymph node syndrome. Eur J Pediatr 141:50-51

9. Mason WH, Jordan SC, Sakai R, Takahashi M, Bernstein B 1985 Circulating immune complexes in Kawasaki syndrome. Pediatr Infect Dis 4:48-51

10. Li CR, Yang XQ, Shen J, Li YB, Jiang LP 1990 Immunoglobulin G subclasses in serum and circulating immune complexes in patients with Kawasaki syndrome. Pediatr Infect Dis 9:544-547

11. Keren G, Wolman M 1984 Can Pseudomonas infection in experimental animals mimic Kawasaki disease? J Infect 9:22-29

12. Murata H 1970 Experimental Candida-induced arteritis in mice: relation to arteritis in the mucocutaneous lymph node syndrome. Microbiol Immunol 23:825-831

13. Cromartie WJ, Craddock JG 1966 Rheumatic-like cardiac lesion in mice. Science 154:283-284

14. Lehman TJA, Walkwer SM, Mahanovsky V, Mc Curdy D 1985 Coronary arteritis in mice following the systemic injection of group B Lactobacillus casei cell walls in aqueous suspension. Arthritis Rheum 28:652-659

15. Rich AR, Gregory JE 1943 The experimental demonstration that polyarteritis nodosa is manifestation of hypersensitivity. Johns Hopkins Med J 72:63-83

16. Onouchi Z, Ikuta K, Nagamatsu K, Tamiya H, Sakakibara Y, Ando M 1995 Coronary artery aneurysms develop in weanling rabbits with serum sickness but not in mature rabbits: an experimental model for Kawasaki disease in humans. J Vasc Dis 46:679686

17. McKenzie KE 1995 Swine as a model in cardiovascular research. In: Tumbleson ME, Schook LB (eds) Advances in Swine Biomedical Research, Vol 1. Plenum Press, New York, pp 7-15

18. Brown DR, Terris JM 1995 Swine in physiological and pathophysiological research. In: Tumbleson ME, Schook LB (eds) Advances in Swine Biomedical Research, Vol 1. Plenum Press, New York, pp 5-6

19. Kirkwood JK, Webster AJF 1984 Energy-budget strategies for growth in mammals and birds. Anim Prod 38:147-155

20. Animal Protection Law 1998 Council of Agriculture Executive Yuan, Taiwan, amended, 2001. Hua-Zong, Yi-Tzi, Taipei, Taiwan. Available at: www.coa.gov.tw/ coa/eng/index.html

21. Lee KT 1986 Swine as animal models in cardiovascular research. In: Tumbleson ME (ed) Swine in Biomedical Research, Vol 3. Plenum Press, New York, pp 14811496

22. Hall TS, Rosengrad BR, Stone CD, Baumgartner WA, Reitz BA 1990 Pig models for heart-lung transplantation research. In: Proceedings of the Second International Symposium on Pig Model for Biomedical Research; Nov 29-Dec 2, 1990; Academia Sinica, Taipei, pp 55-65

23. Sachs DH, Leight G, Cone J, Schwartz S, Stuart L, Rosenberg S 1976 Transplantation in miniature swine, fixation of the major histocompatibility complex. Transplantation 22:559-567

24. Allan JS, Rose JK, Choo JK, Arn JS, Vesga L, Mawulawde JK, Allison K, Madsen JC 1999 Morphometric analysis to predict appropriate donor size for swine-to-human cardiac xenotransplantation. Transplant Proc 31:975-977

25. Note for guidance on quality of biotechnological products 1996 Viral safety evaluation of biotechnology products derived from cell lines of human or animal origin. Monograph of Horse Serum. CPMP/ICH/295/95

26. Janeway CA, Travers P, Walport M, Capra JD 1999 Immune Biology: Immune System in Health and Disease, 4th Ed. Garland Publishing, New York, pp 479-481

27. Price SA, Wilson LM 1997 Pathophysiology: Clinical Concepts of Disease Response of the Body to Immunologic Challenge. Mosby Co, St. Louis, pp 79-80

28. Woolf N 1998 Pathology: Basic and Systemic. WB Saunders Co, London, pp 129-131

29. Johnson KJ, Chensue SW, Kunkel LS, Ward PA 1988 Immunopathology. In: Rubin E, Farber JL (eds) Pathology. J. B. Lippincott Co, Philadelphia, pp 110-113

30. Onouchi Z, Tomizawa M, Goto M, Nakata K, Fukuda M, Goto M 1975 Cardiac involvement and prognosis in acute mucocutaneous lymph node syndrome. Chest 68:297-301

31. Levin M, Holland PC, Nokes TJC, Novelli V, Mola M, Levinsky RJ, Dillon MJ, Barrat TM, Marshall WC 1985 Platelet immune complex interaction in pathogenesis of Kawasaki disease and childhood polyarteritis. BMJ 290:1456-1460

32. Shirahata A, Nakamura I, Asakura A 1983 Studies on blood coagulation and antithrombotic therapy in Kawasaki disease. Acta Paediatr Jpn 25:104-115

33. Cochrane CG 1971 Mechanisms involved in the deposition of immune complex in tissues. J Exp Med 134:755-758 
34. Yamada K, Shirahata A, Shinakai A, Meguro T 1977 Haematological studies on acute febrile mucocutaneous lymph node syndrome with special reference to the plateletthrombus formation and etiology of MCLNS. Acta Paediatr Jpn 81:1263-1267

35. Fritter BS, Lucky AW 1988 The perineal eruption of Kawasaki syndrome. Arch Dermatol 124:1805-1810

36. Yang CC, Lue HC, Wang JK, Wu MH, Wu YN 1990 A detection and follow up study of coronary arterial lesions in Kawasaki disease by two-dimensional echocardiography. Acta Cardiol Sin 6:262-275

37. Newburger JW, Burns JC, Beiser AS, Localzo J 1991 Altered lipid profile after Kawasaki syndrome. Circulation 84:625-631

38. Tanaka N, Naoe S, Masuda H, Tesuo U 1986 Pathological study of sequelae of Kawasaki disease (MCLS) with special reference to the heart and coronary arterial lesions. Acta Pathol Jpn 36:1513-1527
39. Suzuki A, Tomita SM, Komatsu K 2000 Active remodeling of the coronary arterial lesions in the late phase of Kawasaki disease; immunohistochemistry study. Circulation 101:2935-2941

40. Naoe S 2000 Pathology of coronary aneurysms in the young. Abstract (CS12) presented at the 10th Asian Congress of Pediatrics; March 26-30, 2000; Taipei, Taiwan

41. Hausner EA, Orsini JA, Foster LL 1999 Vascular endothelial growth factor in porcine coronary arteries following balloon angioplasty. J Invest Surg 12:15-23

42. Terai M, Yasukawa K, Narumoto S, Taeno S, Oana S, Kohno Y 1999 Vascular endothelial growth factor in acute Kawasaki disease. Am J Cardiol 83:337-339

43. Patchman LM, Herold BC, Davis AT, Hang LM, Schaller JG, Beckwith B 1987 Immune complexes in Kawasaki syndrome: a review. Prog Clin Biol Res 250:193207 